\title{
Endoscopic submucosal dissection of a large squamous cell cancer using the proximal mucosal bridge technique
}

During endoscopic submucosal dissection (ESD) of large esophageal lesions, adjunct strategies are needed to generate adequate tissue tension besides the traditional distal attachment cap [1,2]. These tension-generating maneuvers are moderately effective, require additional devices [3], and can be time consuming. In this video, we demonstrate the successful use of a proximal "mucosal bridge technique" to efficiently and quickly complete ESD of a large squamous cell carcinoma (SCC) in the esophagus, obviating the need for supplementary traction devices ( $\vee$ Video $\mathbf{1}$ ).

A 74-year-old man underwent esophagogastroduodenoscopy and was found to have a large nodular and granular lesion in the middle of the esophagus ( Fig.1). Biopsies revealed SCC in situ and endoscopic ultrasound examination demonstrated that the lesion was limited to the mucosa. The decision was made to pursue en bloc resection via ESD.

Chromoendoscopy with Lugol's solution demonstrated an unstained area measur- ing $50 \mathrm{~mm}$ in length and involving $90 \%$ of the esophageal circumference. Thermocautery marks were placed circumferentially using the retracted tip of a DualKnife (Olympus, Center Valley, Pennsylvania, USA) (> Fig. 2). Initial mucosal incision was performed using the DualKnife at the distal aspect of the lesion after a submucosal lift was achieved by injecting methylene blue mixed with normal saline (Needle Master; Olympus). A nearly complete marginal mucosal incision was then made around the lesion using the IT nano knife (Olympus) while intentionally preserving an intact mucosal margin, $4 \mathrm{~mm}$ wide, at the most proximal aspect of the lesion ( $\triangleright$ Fig. $\mathbf{3}$ ). This "mucosal bridge" was left intact to provide traction during the submucosal dissection portion of the ESD.

With the mucosal bridge acting as an anchor, entry into the dissection plane was readily accomplished and submucosal dissection was then easily carried out using the IT nano knife in the cephalocaudal direction. Upon completion of

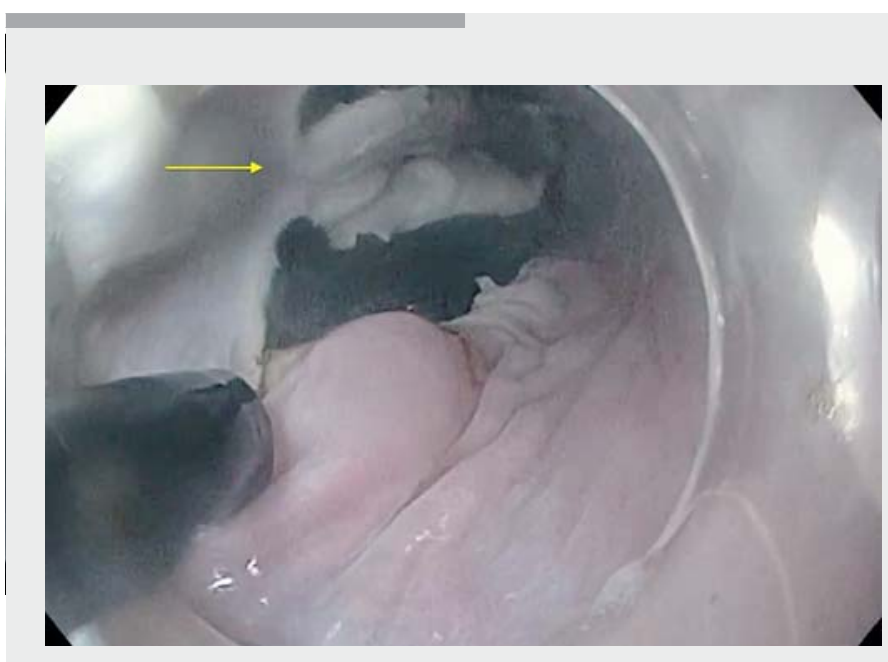

Video 1 Endoscopic submucosal dissection of a large esophageal squamous cell carcinoma using the "proximal bridge technique". The proximal mucosal bridge serves as an anchor and facilitates efficient dissection without the need for additional devices.

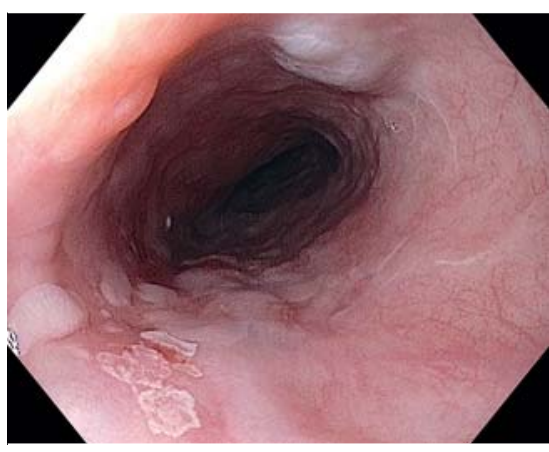

- Fig. 1 A nodular and granular lesion, $4 \mathrm{~cm}$ long and involving $75 \%$ of the circumference, was found in the esophagus.

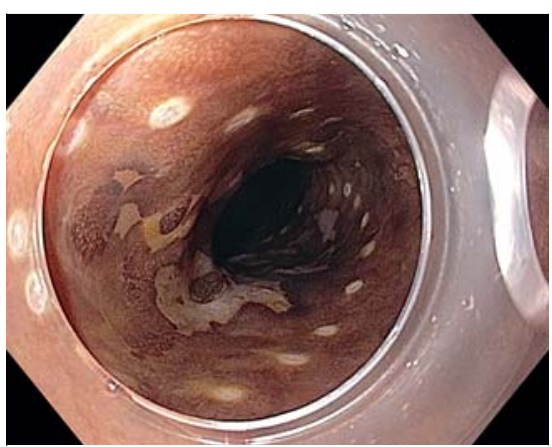

- Fig. 2 Chromoendoscopy with Lugol's solution demonstrated a well-demarcated unstained area measuring $50 \mathrm{~mm}$ in length and involving $90 \%$ of the esophageal circumference.

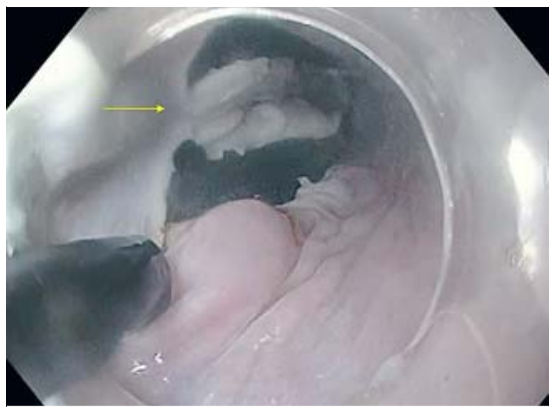

- Fig. 3 Proximal mucosal bridge, which serves as an anchor. 


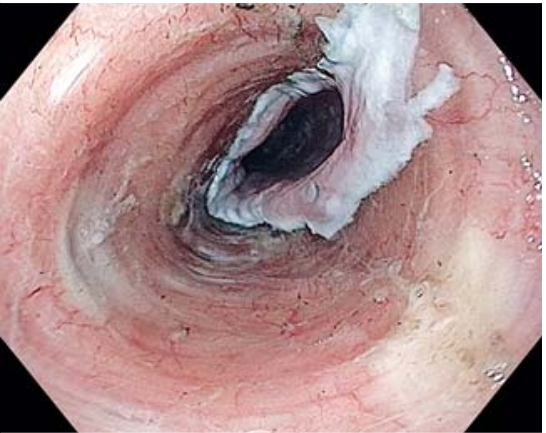

- Fig. 4 The resected area measured $60 \times 50 \mathrm{~mm}$ and the procedure duration was 84 minutes.



- Fig. 5 Final pathology revealed squamous cell carcinoma primarily in situ, with focally superficial invasive cancer into the lamina propria with no lymphovascular invasion and negative deep and lateral margins. the submucosal dissection, the mucosal bridge was finally cut and the lesion detached for complete en bloc resection ( Fig. 4, $>$ Fig. 5).

By acting as a proximal tissue anchor, the "proximal mucosal bridge" provides an alternative method for efficient dissection of lesions in the esophagus given the tubular lumen and limited maneuverability.

Endoscopy_UCTN_Code_TTT_1AO_2AG

\section{Competing interests}

Dr. Draganov is a consultant for Boston Scientific and Olympus Corp. Dr. Yang is a consultant for Boston Scientific.

The authors

\section{Salmaan Jawaid, Dennis Yang, Peter V.} Draganov

Division of Gastroenterology, Hepatology and Nutrition, University of Florida Health, Gainesville, Florida, United States

\section{Corresponding author}

\section{Salmaan Jawaid, MD}

Division of Gastroenterology, Hepatology and Nutrition, University of Florida Health, 3800 NW 79th Terrace Unit 287, Gainesville, FL 32606, United States Fax: +1-281-8274699

Salmaan.jawaid@medicine.ufl.edu

\section{References}

[1] Oyama T. Counter traction makes endoscopic submucosal dissection easier. Clin Endosc 2012; 45: 375 - 378

[2] Maple J, Abu Dayyah B, Chauhan S et al. Endoscopic submucosal dissection. Gastrointest Endosc 2015; 81: 1311-1325

[3] Tsuji K, Yoshida N, Nakanishi H et al. Recent traction methods for endoscopic submucosal dissection. World J Gastroenterol 2016; 22: $5917-5926$

\section{Bibliography}

DOI https://doi.org/10.1055/a-0885-9444

Published online: 2.5.2019

Endoscopy 2019; 51: E209-E210

(C) Georg Thieme Verlag KG

Stuttgart · New York

ISSN 0013-726X

\section{ENDOSCOPY E-VIDEOS}

https://eref.thieme.de/e-videos

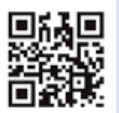

Endoscopy E-Videos is a free access online section, reporting on interesting cases and new

techniques in gastroenterological endoscopy. All papers include a high quality video and all contributions are freely accessible online.

This section has its own submission website at https://mc.manuscriptcentral.com/e-videos 